\title{
ROYAL COLLEGE OF PHYSICIANS
}

\section{REPORT OF THE COMMITTEE ON CHRONIC RHEUMATIC DISEASES}

The Committee appointed in 1950 has met on five occasions, and the following report was passed by the Fellows of the College at the Comitia on July 26, 1951.

Definition.-A precise definition of the chronic rheumatic diseases is difficult, but for practical purposes the field under consideration should include rheumatoid arthritis, osteo-arthritis, spondylitis, gout, and the various forms of non-articular rheumatism, together with the differential diagnosis of these from other conditions which may simulate them.

Introduction.-These diseases are of great importance for economic reasons owing to the large number of man-hours they cause to be lost each year, and equally for humanitarian and medical reasons because of the extent to which they cripple the patient and disrupt family life. Until recently, however, they have received scant attention in the way of organized treatment, teaching, or research.

Early specialization in this field, and the excessive multiplication of posts devoted exclusively to chronic rheumatic diseases leading to further unnecessary fragmentation of general medicine are to be deprecated. However, within the scope of general medicine, the importance of this group of diseases deserves greater recognition for their effective control. In this connection, gastroenterology, cardiology, and neurology may be cited as examples of branches of medicine requiring varying degrees of special training, yet remaining as part of general medicine.

Thus the chronic rheumatic diseases should not generally be a whole-time specialty, but should constitute a special interest within general medicine; alternatively, after appropriate training in general medicine, this specialty could be combined with physical medicine or orthopaedics.

Study in this field should not be allowed to become an easy route to consultant status, and it is recommended that a special diploma should not be established.

An adequate background of general medicine is essential for the diagnosis and treatment of the chronic rheumatic diseases. In addition, however, some special knowledge of orthopaedics, physical medicine, and endocrinology is necessary.

\section{Establishment of Special Centres}

The best method of advancing the study of chronic rheumatic diseases is by the development of special centres throughout the country to the number of approximately one per region; this might include special centres already in existence, some of which might need expansion. These centres should be primarily concerned with research and teaching, but would also influence the general standard of treatment. They should be in close liaison with the medical department of a general hospital, and should be linked with university teaching and research departments, including those of the basic sciences. They should be the joint responsibility of the University, the Teaching Hospital, and the Regional Hospital Board. Each centre should be in the charge of a Physician with good general medical training and special experience in this field, and the junior staff should consist of house physicians and registrars, preferably in the latter part of their training.

While it is recognized that the recommended special centres would mean special allocation of beds for the treatment of chronic rheumatic diseases, it is felt that the aggregation of chronic rheumatic patients in these beds, as well as setting free beds in general wards, might decrease the average duration of stay in hospital by reason of the special treatment available.

\section{Functions of Centres}

Research.-Research projects would be pursued under the direction of the Physician-in-charge, with the co-operation of the appropriate department of the associated Hospital and University.

Teaching.

(a) Special training for those physicians who wish to adopt this specialty as their main work.

(b) Training courses for general physicians, specialists in physical medicine, and orthopaedic surgeons who wish to be seconded to these centres for this purpose.

(c) Short courses for general practitioners. 
(d) Undergraduate teaching in co-operation with the medical department of the associated medical school.

In the past the chronic rheumatic diseases have often received inadequate attention in undergraduate education. A regular series of lecture-demonstrations should form a part of the final year of clinical study and that, in some cases, a short period of clerking in the wards of the rheumatic unit would be of considerable value to the student, in view of the high incidence of these diseases in general practice. An improvement in undergraduate instruction in this subject would contribute to an improvement in the treatment of chronic rheumatic disease.

Training.-It is desirable that a physician who aims at obtaining charge of such a special centre should have held the appointment of house physician for 6 months, either during his year of provisional registration or subsequently, and that he should receive the following minimal full-time training:

2 years in a registrar or comparable post in general medicine

2 years in a registrar or comparable post in a rheumatic centre

6 months' training in orthopaedics

6 months' training in physical medicine

1 further year in one of the following:

(a) study abroad,

(b) research,

(c) further experience in general medicine and its branches, endocrinology, neurology, physical medicine, or orthopaedics.

The minimal training after completion of house officer duties is thus envisaged as 6 years, a period comparable with that of other branches of medicine. The final year leaves a large margin of individual choice.

The M.R.C.P.(Lond.), or an accepted equivalent, should normally be taken before special study of the chronic rheumatic diseases is commenced, but it is recognized that in exceptional circumstances it may be permissible for the trainee to sit for his higher medical qualification during his period of special training.

\section{Conclusions}

(1) The organization of the treatment of the chronic rheumatic diseases should receive special consideration.

(2) Special centres for chronic rheumatic diseases should be developed throughout the country, approximately one per region.

(3) These centres should be primarily concerned with research and teaching.

(4) There should be close liaison between these centres and a general hospital, and university teaching and research departments, including those of the basic sciences.

(5) Each centre should be in the charge of a Physician with good general training and special experience in this field. He should have a higher qualification in medicine and should have a staff of house physicians and registrars.

(6) The minimal training of a Physician-in-charge of such a centre should be 6 months as house physician, either during his year of provisional registration or subsequently, 2 years in a registrar or comparable post in general medicine, and a further 4 years' special training.

\section{Members of THE COMMITTEE}

Dr. W. Russell Brain (President).

Dr. Anthony Feiling.

Sir John Conybeare.

Dr. Frank Howitt.

Dr. W. S. C. Copeman.

Prof. W. G. Barnard.

Dr. E. T. Conybeare.
Prof. L. S. P. Davidson.

Dr. G. D. Kersley (Secretary).

Sir Ernest Rock Carling.

Dr. E. G. L. Bywaters.

Dr. F. S. Cooksey.

Mr. H. Osmond-Clarke.

Sir Harold Boldero. 